\title{
CARACTERIZAÇÃO DA DIVERSIDADE GENÉTICA EM Alcantarea patriae (BROMELIACEAE) POR MEIO DE MARCADORES MICROSSATÉLITES
}

\author{
Ugo Cesar Sartori Bernardi' \\ Aléxia Gonçalves Pereira ${ }^{2}$ \\ Vitor Manhães ${ }^{3}$ \\ Lucimara Cruz de Souza ${ }^{4}$ \\ Kelmer Mozer Moro ${ }^{5}$ \\ Alessandra Abreu Rodrigues Vieira ${ }^{6}$ \\ Fábio Demolinari de Miranda ${ }^{7}$
}

Resumo: A familia Bromeliaceae ocorre em sua maioria nas regiões neotropicais destacando se devido ao elevado número de espécies endêmicas. Essa família tem sofrido com o extrativismo ilegal de várias espécies em suas populações naturais, o que promove erosão genética e redução no potencial adaptativo destas populações. Os marcadores microssatélites são ferramentas úteis e eficientes para estudos de diversidade genética vegetal, entretanto existem espécies para as quais, esses marcadores ainda não foram descritos. Uma forma alternativa de uso é a amplificação heteróloga. No presente estudo, utilizou-se primers desenvolvidos para Pitcairnia geyskesii e para Pitcairnia albiflos em Alcantarea patriae de maneira a estimar a diversidade e a estrutura genética de populações naturais. As análises demostraram a existência de diferenciação genética entre populações amostradas e a subdivisão em dois grupos genéticos, além de indicar baixo fluxo gênico e efeitos de endogamia.

Palavras-chave: Variabilidade genética; Estruturação populacional; Transferibilidade; Heterozigosidade; Diferenciação populacional.

\footnotetext{
${ }^{1}$ Mestrando em Genética, Conservação e Biologia Evolutiva/INPA, Brasil. E-mail: ugocesars@gmail.com.

2 Bióloga/UFES, Brasil. E-mail: alexiagp@gmail.com.

${ }^{3}$ Doutorando em Ciências Biológicas/ Botânica/UFRJ, Brasil. E-mail: manhaesvc@gmail.com.

${ }^{4}$ Mestranda em Genética e Melhoramento/UFES, Brasil. E-mail: lucimaracruz15@hotmail.com.

${ }^{5}$ Ciências Biológicas/UFES, Brasil. E-mail: kelmer.moro@gmail.com.

6 Doutoranda em Genética e Melhoramento/ UFES, Brasil. E-mail: abreuepires@gmail.com.

7 Prof. Doutor em Genética e Melhoramento/UFES, Brasil. E-mail: fademolinari@yahoo.com.br.
} 